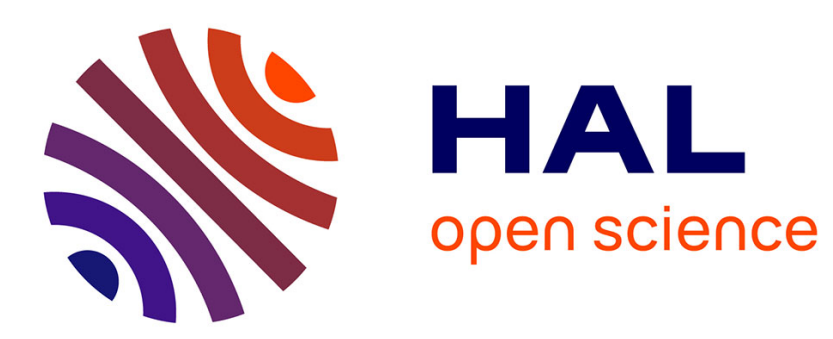

\title{
Polycrystalline microstructure, cubic elasticity and nucleation of high-cycle fatigue cracks
}

Maxime Sauzay, Thomas Jourdan

\section{To cite this version:}

Maxime Sauzay, Thomas Jourdan. Polycrystalline microstructure, cubic elasticity and nucleation of high-cycle fatigue cracks. International Journal of Fracture, 2006, 141 (3-4), pp.431-446. 10.1007/s10704-006-9005-x . cea-02511911

\section{HAL Id: cea-02511911 https://hal-cea.archives-ouvertes.fr/cea-02511911}

Submitted on 19 Mar 2020

HAL is a multi-disciplinary open access archive for the deposit and dissemination of scientific research documents, whether they are published or not. The documents may come from teaching and research institutions in France or abroad, or from public or private research centers.
L'archive ouverte pluridisciplinaire HAL, est destinée au dépôt et à la diffusion de documents scientifiques de niveau recherche, publiés ou non, émanant des établissements d'enseignement et de recherche français ou étrangers, des laboratoires publics ou privés. 
Editorial Manager(tm) for International Journal of Fracture

Manuscript Draft

Manuscript Number: FRAC551R1

Title: Polycrystalline microstructure, cubic elasticity and nucleation of high-cycle fatigue cracks

Article Type: Original Research

Section/Category:

Keywords: polycrystal, scatter, neighbour grains, crystalline elasticity, high-cycle fatigue, crack nucleation

Corresponding Author: Dr maxime sauzay,

Corresponding Author's Institution: CEA

First Author: Maxime Sauzay, Dr

Order of Authors: Maxime Sauzay, Dr; thomas jourdan; maxime sauzay, Dr; Maxime Sauzay, Dr

Manuscript Region of Origin:

Abstract: It is well-known that high-cycle fatigue cracks usually nucleate in surface well-oriented grains with a high Schmid factor. A numerical evaluation of the effect of crystalline elasticity anisotropy (which is often neglected) on the stress state in well-oriented grains is presented. Each of these grains is located at the free surface of an aggregate. The other crystallographic orientations are random. Numerous finite element computations are carried out for evaluating the effect of the neighboring grain orientations. Resolved shear stress and normal stress averages are given, as well as scatter parameters and histograms. Several metals, orientations, and loading conditions are considered. For common (anisotropic) metals/alloys such as copper and austenitic steels, the local average resolved shear stress is about $18 \%$ smaller than the macroscopic value which induces a Schmid factor value with respect to the macroscopic tensile stress of 0.41 instead of the classical 0.5 value. Relative scatters in resolved shear stress and corresponding normal stress are high (respectively $\pm 22 \%$ and $\pm 38 \%$ ). These high scatter values computed for small applied loads can explain many observations taken from the literature showing a large scatter in the plastic slip line feature, dislocation microstructure, microstructurally short crack nucleation, and propagation rate among well-oriented surface 
grains. Finally, the effects of some geometrical parameters are evaluated (2D/3D effects, subsurface grains....). 


\title{
Polycrystalline microstructure, cubic elasticity, and nucleation of high-cycle fatigue cracks
}

\author{
MAXIME SAUZAY and THOMAS JOURDAN \\ DEN-DMN-SRMA, CEA, bât. 455, 91191 Gif-sur-Yvette cedex, France
}

\begin{abstract}
It is well-known that high-cycle fatigue cracks usually nucleate in surface welloriented grains with a high Schmid factor. A numerical evaluation of the effect of crystalline elasticity anisotropy (which is often neglected) on the stress state in well-oriented grains is presented. Each of these grains is located at the free surface of an aggregate. The other crystallographic orientations are random. Numerous finite element computations are carried out for evaluating the effect of the neighboring grain orientations. Resolved shear stress and normal stress averages are given, as well as scatter parameters and histograms. Several metals, orientations, and loading conditions are considered. For common (anisotropic) metals/alloys such as copper and austenitic steels, the local average resolved shear stress is about $18 \%$ smaller than the macroscopic value which induces a Schmid factor value with respect to the macroscopic tensile stress of 0.41 instead of the classical 0.5 value. Relative scatters in resolved shear stress and corresponding normal stress are high (respectively $\pm 22 \%$ and $\pm 38 \%$ ). These high scatter values computed for small applied loads can explain many observations taken from the literature showing a large scatter in the plastic slip line feature, dislocation microstructure, microstructurally short crack nucleation, and propagation rate among well-oriented surface grains. Finally, the effects of some geometrical parameters are evaluated (2D/3D effects, subsurface grains....).
\end{abstract}




\section{Introduction}

High-Cycle Fatigue (HCF) corresponds to small applied stresses and high numbers of cycles

to failure $\left(\mathrm{N}_{\mathrm{f}}>10^{5}\right.$ cycles). It is usually divided into two stages. During stage $\mathrm{I}$, for polycrystals without defect or inclusion, cracks appear along slip bands in well-oriented grains and then follow the most loaded slip systems in the neighboring grains $[1,2]$. Microstructure greatly influences this stage. Then, during stage II, macroscopic cracks propagate along planes with the maximal normal stress [1]. For high-cycle fatigue stage I is much longer than stage II, therefore the number of cycles to failure depends strongly on the microstructure. This can be checked at the macroscopic scale (due to texture effect [3]). This scatter is observed at the grain scale too concerning the first part (crack nucleation) or the second part of stage I (propagation of microstructurally short cracks which have lengths smaller than a few grain sizes). The local microstructure parameters are indeed very influential on crack nucleation, propagation, and eventually arrest (depending on the grain orientations). This could partially explain the high scatter which is usually observed at the macroscopic scale (number of cycles to failure) [4].

Concerning crack nucleation, observations showed the influence of grain orientation and plastic slip mechanisms [3,5-8]. Applied stresses during high-cycle or giga-cycle tests are small, which is why volume element behavior is generally supposed to be elastic. In this regime, plasticity takes place preferentially in well-oriented grains with a high Schmid factor on one of their slip systems [8]. In these grains, plastic slip is localized along slip lines and in slip bands (Persistent Slip Bands for example). Cyclic plasticity induces higher and higher surface roughness, stress concentration, and stored energy. These phenomena finally lead to crack nucleation along activated slip planes/bands. Using the surface slip traces observed on polished tested specimen, authors tried to deduce the Schmid factors corresponding to the 
activated slip planes. Electron Back Scattered Diffraction permitted them to measure crystallographic orientations and to deduce Schmid factors with a better knowledge of activated slip systems [5-7]. Following the EBSD study of Mineur [5], cracks nucleate generally in grains with high Schmid factors. But, few data exist concerning the influence of the neighboring grains and the induced scatter. Following EBSD studies, about one half of the grains where no slip band appears are well-oriented grains with a non-negligible normal component of the Bürgers vector (component which is perpendicular to the free surface). On the contrary, slip bands appear in numerous grains with smaller Schmid factors. The influence of the neighboring grain orientations could explain these surprising observations. In addition, the attempt made by Winter et al. to relate the dislocation microstructure of each grain to the corresponding tensile axis was not always successful [8]. Their Transmission Electronic Microscopy (TEM) observations of cyclically induced dislocation microstructures in copper polycrystals showed that grains with very close crystallographic orientations could present varied dislocation microstructures (only matrix or ladders in the small strain range).

Models have been proposed for predicting plastic slips and numbers of cycles to crack nucleation in well-oriented grains either in the bulk [9] or at the free surface [10]. Using a hypothesis of uniform stress, Hoshide and Socie predicted nucleation and evolution of fatigue microcrack networks and investigated the influence of the loading conditions (tensioncompression, shear....) [11]. Using either a homogeneization modelling (Doquet et al. [12]) or Finite Element plane strains computations (Bennett and McDowell [13]), authors computed polycrystal distributions of plastic slips which are driving forces for crack nucleation. Plastic slip distributions were shown to be strongly heterogeneous, particularly for small applied stress [13]. But, almost all of these studies neglect the effect of crystalline elastic anisotropy. In fact, for a large number of metals or alloys, crystalline elasticity is very anisotropic at the single crystal or grain scale. Considering all possible tensile directions, the ratio between the 
maximum and minimum Young (or shear) modulus is equal to about 3 for austenite and copper, and about 2.5 for ferrite (Table 1). An interesting phenomenon reported in $[14,15]$ is the high scatter in the stresses in grains (with a given crystallographic orientation) all the more as the material has a strong anisotropy. Using a generalization of the equivalent inclusion method and taking into account the crystalline elasticity of the well-oriented grain and of its direct neighboring grains, Teng and Lin showed that crystalline elasticity strongly affects plastic slip and the resolved shear stress in a slip band located in a well-oriented grain [14]. Using Finite Element computations on a 2D aggregate, Pommier showed that the stress tensor in a given grain with a $<100>$ tensile axis is strongly affected by the neighboring grain orientations [15]. A scatter of about $\pm 35 \%$ is obtained for copper. In addition, scatter depends on the anisotropy factor.

In elasticity domain corresponding to high-cycle fatigue, stress distribution in a given grain could largely depend on the crystallographic orientations of the surrounding grains. This scatter could be responsible for early initiation of short cracks in the most loaded welloriented grains. In spite of the two previous modelling attempts, no theoretical study evaluating the stress-strain and crack initiation scatter in well-oriented grains (and others) has been published. This article is dedicated to such an attempt. Monte-Carlo Finite Element computations are carried out. Either type A/B well-oriented grains or $<100>$ grains are considered. The considered grain is located at the free surface of a $3 \mathrm{D}$ aggregate which is embedded in a matrix. The crystallographic orientations of the neighboring grains are random. The influence of elasticity anisotropy (aluminium, ferrite, copper, austenite) and loading condition (tension-compression, shear, equibiaxial loading) is extensively studied. For each orientation, metal, and loading condition, about 60 Finite Element computations are carried out, corresponding to 60 sets of random orientations of the neighboring grains. Average and scatter values are given for both shear stress and normal stress on well-oriented slip systems 
because these values are important for predicting crystalline crack initiation and propagation. Concentration effects due to particular neighbor orientations are evaluated which gives upper and lower values with respect to the computations using random orientations. In addition, influence of the orientations of the grain layer under the considered grain is evaluated. Finally, the consequences of the stress-strain scatter on the local damage evolution are discussed. These results could help to better understand crack nucleation mechanisms and experimental observations of cyclic microplasticity and damage nucleation.

\section{Computation hypothesis}

As small applied stresses are considered, only elastic behaviors are used. Grains obey crystalline elasticity whereas matrix (the whole polycrystal) obeys isotropic elasticity. Four metals with various crystalline elasticity anisotropy are considered: aluminium, ferrite, copper, and austenite. In fact, published observations of microplasticity and crack nucleation micromechanisms often concern these metals. The crystallographic structure of ferrite is Body Centred Cubic (BCC) whereas the other metals present a Face Centred Cubic (FCC) structure. Therefore, cubic elasticity can be used at the grain scale for all four metals. Three elasticity parameters are involved: $\mathrm{C}_{11}, \mathrm{C}_{12}$, and $\mathrm{C}_{44}$. Cubic elasticity laws can be written with respect to the crystallographic axis [16]:

$$
\begin{aligned}
& \sigma_{11}=C_{11} \varepsilon_{11}+C_{12} \varepsilon_{22}+C_{12} \varepsilon_{33} \\
& \sigma_{22}=C_{12} \varepsilon_{11}+C_{11} \varepsilon_{22}+C_{12} \varepsilon_{33} \\
& \sigma_{33}=C_{12} \varepsilon_{11}+C_{12} \varepsilon_{22}+C_{11} \varepsilon_{33} \\
& \sigma_{12}=2 C_{44} \varepsilon_{12} \\
& \sigma_{13}=2 C_{44} \varepsilon_{13} \\
& \sigma_{23}=2 C_{44} \varepsilon_{23}
\end{aligned}
$$


If other axis are considered, cubic elasticity law expressions are more complicated. The respective elasticity anisotropy of each metal can be estimated by the calculation of a dimensionless coefficient defined as follows:

$$
a=2 \frac{C_{44}}{C_{11}-C_{12}}
$$

In Table 1 crystalline elasticity parameters are displayed, as well as corresponding anisotropy coefficients and macroscopic isotropic elastic coefficients, $\mathrm{E}$ and $v$ (for polycrystals without texture). Aluminium is the less anisotropic metal, ferrite is rather anisotropic, and austenite and copper are strongly anisotropic. As mentioned before, the anisotropy coefficient is equal to the ratio between the maximal and minimal elasticity shear moduli (considering all possible shear systems in a continuous framework).

Three scales are involved in our model. First, one main grain is considered. Its crystallographic orientation is kept constant. Second, neighboring grains have random orientations. And third, the small aggregate is embedded in a matrix which mimics the whole polycrystal. As small cracks nucleate at the free surface, the aggregate is located at the free surface of the matrix. Cracks are supposed to nucleate because of cyclic crystalline plasticity. For the FCC (BCC) metals, the slip systems are defined by normal directions $\{111\}$ and slip directions $<110>$. For BCC metals, at least two slip system families are involved $(\{110\}$ $<111>$ and $\{112\}<111>$ ). Cracks nucleate in well-oriented grains, which present a slip system $(n, m)$ with a macroscopic Schmid factor equal to its maximal value, 0.5 (computed with respect to the macroscopic tensile stress). The (unit) normal vector to the slip system is denoted as $n$ whereas the (unit) slip vector is denoted as $m$. Both the $n$ and $m$ vectors are inclined at $45^{\circ}$ with respect to the tensile direction (Fig. 1 a)). In this study, the following directions of the well-oriented slip system have been chosen: $n=1 / \sqrt{ } 3(1,1,1)$ and $m=1 / \sqrt{ } 2(1,0$,1) for FCC metals. For the BCC metal, only one slip system family is considered and the 
well-oriented slip system directions are: $n=1 / \sqrt{ } 2(1,0,-1)$ and $m=1 / \sqrt{ } 3(1,1,1)$. Among welloriented slip planes, type A and type B facets can be distinguished (Fig. 1 b)). For type B facets, both vectors are inclined at $45^{\circ}$ with respect to the free surface. But, for type A facets, both vectors are located in the free surface. For tension-compression, both facets correspond to well-oriented slip systems. But, type B facets are supposed to be more dangerous than type A because they induce relief formation whereas A facets induce only shearing inside the free surface without relief formation. In addition, recent computations showed that type B facets induce higher plastic slip inside well-oriented grains [17] or inside slip bands [10] than type A. Another particular crystallographic orientation is considered for studying the influence of the orientation. These complementary computations will permit the comparison with Pommier's which concern the same orientation [15]. The crystallographic directions are the same as the macroscopic ones. This gives a [100] tensile direction and a reference Schmid factor equal to 0.408 (obtained on 8 slip systems). In addition to tension-compression, two other macroscopic loading conditions are applied in the case of austenite: shear and equibiaxial loadings. For shear, only type A facets are involved in crack nucleation because they correspond to the lonely slip systems with maximal shear stress (at the macroscopic scale) [17]. For equibiaxial loading, only type B facets are involved [17].

The direct neighboring grains present random orientations. For each case (crystallographic orientation of the middle surface grain, metal, loading condition), 60 sets of random crystallographic orientations of the neighbors are considered, which induces 60 Finite Element computations. It was checked that the cumulated probability of the resolved shear stress is quite the same using either 40 or 60 sets of random orientations. But, neighboring grain configurations giving values a bit more extreme than the ones obtained using 60 sets of random orientations can be found as it will be discussed later (neighbor configurations with "hard" and "soft" grains). 
The Finite Element method is used for evaluating local stress tensor. The mesh shown in Figure 2 b) consists of a small aggregate of 7 cylinders with a hexagonal base. The middle grain has a particular crystallographic orientation (type B for example) (Figure 2 c)), embedded at the free surface of a large matrix (Figure 2 a)). The hexagons have edges of 20 $\mu \mathrm{m}$ and a thickness of $50 \mu \mathrm{m}$. Each element in a hexagon has the following dimensions: $5 \mu \mathrm{m}$ x $5 \mu \mathrm{m} \times(50 / 3) \mu \mathrm{m}$. The dimensions of the matrix are $2 \mathrm{~mm} \times 2 \mathrm{~mm} \times 0.5 \mathrm{~mm}$. It should be noticed that only the ratios between these lengths affect the stress values. The mesh quality is checked carrying out computations with a finer grid. Numerical errors are smaller than a few percents of the resolved shear stress. For the tension-compression loading, uniform horizontal (x-axis) displacements are prescribed at one matrix lateral face which is perpendicular to the x-direction (Fig. 2 a)). The opposite side remains fixed. The four other faces are traction free. The adopted value of displacement corresponds to a macroscopic tensile loading of $300 \mathrm{MPa}$. Another value could have been chosen as the problem is linearly elastic. Some other node displacements are fixed in order to avoid rigid body motion indetermination. In equibiaxial loading, additional y-direction displacements are prescribed at the two sides perpendicular to the y-axis. In torsion, the y-direction (x-direction) displacements at the two opposite sides perpendicular to the $\mathrm{x}$-axis (y-axis) are specified. The two horizontal sides are traction free. For each set of neighbor orientations, middle grain mean resolved shear stress and normal stress are calculated as well as the values at the surface in the center of this grain. Then, the averages and scatter parameters can be computed considering the 60 results. Another mesh was used to study the effect of the grains located under the previous aggregate on the scatter of the resolved shear stress in the middle grain. For this purpose, a layer of sub-surface grains is added. To simplify, the new aggregate consists of two similar grain layers. The matrix remains the same except for the thickness, which is now of $0.55 \mathrm{~mm}$. The number of grains is then 14 instead of 7 (Figure $2 \mathrm{~d}$ )). 


\section{Results of the Finite Element analysis}

Results are given for stress averages and scatter parameters first for well-oriented type B grain and tension-compression (Tables 2 and 3, Figures 3-7). The average resolved shear, $\tau_{\mathrm{ave}}$, is computed using 60 computations for each studied case: metal/ middle grain orientation/loading condition. It is influenced by the elasticity anisotropy (Table 2, Figure 3). For each computation, the stress averaged on the whole oriented grain is used. Then the final average value is computed taking into account values given by 60 computations. For the most anisotropic metals, the local resolved shear stress represents only about $82 \%$ of the macroscopic shear stress. But, the effect on the average normal stress is smaller (increase of only $+4 \%$ with respect to the macroscopic shear stress) (Table 3, Figure 3). The scatter can be evaluated using either the minimum/maximum values, $\tau_{\min }$ and $\tau_{\max }$, or the standard deviation, $\Delta \tau$. Each is computed using the 60 Finite Element results for each metal/middle grain orientation/loading condition case. Two different scatter parameters are used: either the relative amplitude $\left(\tau_{\max }-\tau_{\min }\right) /\left(2 \tau_{\text {ave }}\right)$ or the relative standard deviation multiplied by a factor of 3, $3 \Delta \tau / \tau_{\text {ave }}$ (Table 2). This last parameter is in fact used by Pommier [15] who assumed that a gaussian probability model could be applied. For a gaussian distribution, $99.7 \%$ of the values are included in the $\left[\tau_{\mathrm{ave}}-3 \Delta \tau, \tau_{\mathrm{ave}}+3 \Delta \tau\right]$ range. It is checked that the computed distributions can reasonably be described using gaussian distributions. But, the use of a gaussian probability model is in fact a bit questionable because even if considering all possible sets of neighboring grain orientations, only limited stress values should be obtained in well-oriented grains. And, in the case of a gaussian probability model, unlimited values can be reached. The two scatter parameters are computed for the normal stress, $\sigma$, as well (Table 3 ). For the most anisotropic metals, the gaussian scatter parameter is high for both resolved shear stress $( \pm 21 \%)$ and normal stress $( \pm 38 \%)$. Figures 4 and 5 display the resolved shear stress and 
normal stress for 60 microstructures. Figure 6 displays the cumulated probability curve of the resolved shear stress. The normal stress scatter is higher than that computed for resolved shear stress one. As will be discussed later, this high scatter induces higher or smaller stresses in some of the well-oriented grains and therefore faster or slower crack nucleation depending on the orientations of the neighboring grains. It should be noticed that the gaussian scatter parameter, $3 \Delta \tau / \tau_{\text {ave }}$, is generally higher than the scatter parameter using the amplitude, $\left(\tau_{\max }-\right.$ $\left.\tau_{\min }\right) /\left(2 \tau_{\text {ave }}\right)$, but their values generally remain close. For ferrite (medium) elasticity anisotropy, non-negligible effects are shown. The gaussian scatter parameters for $\tau$ and $\sigma$ are $15.3 \%$ and $27.9 \%$, respectively. For aluminium, effects are small as expected. This metal is indeed very weakly anisotropic (Table 1). And if the grain behavior is isotropic, there is no stress heterogeneity between grains. The variations of the scatter parameters depending on the elasticity anisotropy factor are given in Figure 7. The adjusted curves displayed in Figures 3 and 7 have been found using second order polynomials. The coefficients are given in Table 4 . On the theoritical point of view, the average and scatter factors (with respect to the macroscopic stress) do not depend only on the elasticity anisotropy factor. As three crystalline elasticity parameters are involved, the normalized local stresses depend on two dimensionless elasticity parameters (and not only on the anisotropy parameter, $a$ ). But, it should be noticed that the normalized averages and scatters obtained for copper and austenite are very close (Figures 3 and 7). Their $a$ ratios are equal but their $C_{12} / C_{44}$ ratios are a bit different. Therefore, the curves given in Figures 3 and 7 should nevertheless give good approximations for all cubic metals and alloys, except if the considered anisotropy ratios are much larger or smaller than those that were studied.

Then, the influence of the loading condition is studied. In addition to tension-compression, both shear and equibiaxial loadings are considered. These three loading conditions are compared for the same value of Tresca stress (two times the highest shear stress, 2T). Only 
austenite is considered in the following (metal with a high anisotropy coefficient). Concerning the resolved shear stress, shear (type A well-oriented grains) and tension-compression give about the same average and scatter values. The average local normal stress obtained during shear test is rather small $(0.06 \mathrm{~T})$ because there is no corresponding macroscopic tensile stress (pure shear). As linear computations are carried out and alternate cycles are considered, the opposite normal stress value obtained for a particular set of crystallographic orientations is obtained during the reverse part of the cycle. If the normal stress amplitude average is computed instead of the normal stress averages (still using the results of 60 Finite Element computations), then a value of $0.15 \mathrm{~T}$ is obtained which is equal to $18 \%$ of the local shear stress average. In fact, non- negligible tension or compression stresses can be obtained for particular neighbor orientations sets $(+0.39 \mathrm{~T}$ and $-0.44 \mathrm{~T})$. If an alternate shear loading is applied, then, during the reverse part of the cycle, normal stresses of $-0.39 \mathrm{~T}$ and $+0.44 \mathrm{~T}$ are obtained in the well-oriented grains belonging to the corresponding aggregates. Therefore, for the corresponding set of neighboring grains, the maximal normal stress magnitude is equal to $52.3 \%$ of the local shear stress magnitude average. These tension-compression stresses could promote short crack nucleation and propagation during the beginning of stage I. Equiaxial loading involves type B slip systems only [17]. With respect to the classical tensioncompression loading, equibiaxial loading leads to similar results except for the normal stress averaged on each grain which is generally smaller ( 0.86 versus 1 for type A facet and 1.04 for type B facet).

Stress tensor triaxiality effects can be studied using Table 9. For austenite, tensioncompression, and type B grain, the stress state remains close to uniaxiality. But, nonnegligible other stress components can be obtained for particular neighboring grain orientation sets. They can reach $25 \%$ of the local uniaxial stress (averaged on 60 
computations). As expected, for these small stress components, the relative scatter can be huge (Table 5).

Finally, the crystallographic orientation effect of the considered middle grain is evaluated. For austenite and tension-compression, three crystallographic orientations are considered. Either well-oriented type A and type B grains are considered or a grain in which crystallographic axis are the same as the macroscopic axis. For this last orientation, the tensile axis is a [100] crystallographic axis (multiple slip orientation with 8 slip systems with a macroscopic Schmid factor of 0.408). Tables 6 and 7 permit us to compare these three orientations. It can be observed that there is a non-negligible effect of the crystallographic orientation on the scatter. For example, the scatter on the resolved shear stress is multiplied by a factor 2 when considering a grain with a [100] tensile axis instead of a type A grain (Table 6). And, the normal stress scatter in the same grain is 0.7 times smaller than in a type B grain (Table 7). It should be noticed that our results are close to Pommier's gaussian scatter parameter based on this last orientation [15]. Following our computations, a relative scatter parameter on the [100] tensile stress of $30.2 \%$ is obtained whereas a scatter parameter equal to $35 \%$ was computed by Pommier. These values are computed at a Gauss point located near the free surface, in the middle of the grain surface. The scatter parameter is the standard deviation based one (3 $\Delta \sigma / \sigma_{\mathrm{av}}(\%)$ ). Pommier's computations are 2D (no matrix under the aggregate could enhance the scatter because the grains can deform more easily) whereas our computations are 3D which could introduce a bias in the comparison. That is why $2 \mathrm{D}$ computations are carried out as well (using a thin mesh without any matrix under the surface aggregate). A scatter parameter equal to $31.2 \%$ is obtained which is very close to the $3 \mathrm{D}$ result. In addition, Pommier did not only consider direct neigboring grains but also other grains with random orientations in the aggregate plane [15] which could slightly increase the 
scatter. But, it can be deduced from this comparison that the effect of direct neighoring grains is much more important than the other grains.

\section{Discussion}

\subsection{DISCUSSION OF SOME HYPOTHESIS}

For the sake of simplicity, only surface neighboring grains are considered in the previous part. Grains with particular orientations located under the surface layer of grains are not taken into account. For evaluating the influence of these grains which are located just below the considered surface grains, computations using another mesh are carried out. This mesh contains one upper surface grain layer in addition to another layer, located just below that of the surface. Therefore, this aggregate contains 14 grains (Fig. 2 d)) instead of 7 (Fig. 2 b)). As before, the aggregate is embedded in a macroscopic medium. The crystallographic orientation of the central grain is kept constant but the others are random. Finally, 60 microstructures are built and 60 Finite Element computations are carried out. The obtained scatter is very close to that computed using only 6 neighboring grains instead of 13 (Table 8). Therefore for surface grains, crystalline elasticity and regular hexagonal grains, the influence of the grains below the surface grains on the scatter is not very important. Taking into account an additional grain layer does not change our scatter evaluations very much.

Before discussing the consequences of the scatter evaluations, their statistical representativity should be discussed. In fact, concerning the study of fatigue crack initiation mechanisms, it is important to know if enough random aggregates are considered for evaluating reliable values of the maximum shear stress and scatter parameters of well-oriented grains located at the free surface of a volume element. First, it should be noticed that increasing the number of considered neighboring grain sets does not change the computed scatter parameters very much. For example, using 40 and using 60 sets of orientations give very close values of 
average and scatter values (for given metal, loading condition, and orientation of the middle grain). Second, as it is important to compute the maximum shear stress value and to determine for which orientations of the neighboring grains it is obtained, complementary computations on simplified configurations are carried out. It is well-known that for elastic composites, stress concentrates in hard phase (for example in fibers with a high Young modulus). Therefore soft phase stress is smaller than macroscopic stress (matrix with a low Young modulus). As it was mentioned, copper or austenitic steel polycrystals present hard grains (tensile direction parallel to the [111] direction) and soft grains (tensile direction parallel to the [100] direction). The ratio between the extreme Young moduli is about 3. It can be guessed that hard neighboring grains aligned with the considered middle grain along the tension axis would increase the stress magnitude inside this middle grain. But if these hard neighboring grains are not aligned with the middle grain along the tension axis (but are on its sides), they would decrease the stress magnitude in it because stress concentrates preferentially in these hard grains. Therefore, the middle grain stress is smaller than those without these neighboring grains. For soft neighbouring grains, inverse effects should be expected. Two extreme aggregate configurations are finally considered. The first one should lead to a maximum stress concentration inside the middle (well-oriented) grain (two aligned hard grains whereas the other neighboring grains are soft, see Fig. 8). The second configuration is the opposite. Finally, an "average" configuration is considered: the middle (well-oriented grain) is directly embedded in the matrix without any neighboring grain effect. Results are given in Table 9. The simplified "average" configuration gives results very close to the average computed using 60 random neighboring grain configurations (first line of Table 9). This means that the self-consistence hypothesis is true: on average the interaction of grains of a given orientation with the polycrystal is the same as with the macroscopic medium (homogeneized material). The maximum (minimum) value obtained with the two extreme 
configurations (see lines 2 and 3 of Table 9) is a bit higher (smaller) than the maximum value computed using the 60 random neighboring grain orientation sets. This reinforces the physical interpretation based on the effects of hard and soft grains. The extreme values obtained with the simplified configurations are nevertheless close to the ones obtained using the random configurations. The maximum (minimum) value is $5 \%$ higher (10\% smaller). This shows that 60 random configurations permit us to compute a reasonable estimation of the maximum resolved shear stress reached in the well-oriented grains of a polycrystal. And, simplified configurations could be used for evaluating the extreme values with a very reduced computation cost.

\subsection{CYCLIC MICROPLASTICITY}

For a given central grain crystallographic orientation (type A or type B for example), loading condition, and metal, the resolved shear stress and normal stress averages (using 60 computations) are affected by the cubic elasticity anisotropy coefficient (Figure 3). For austenite and all loading conditions (tension-compression (type A or B), shear (type A), and equibiaxial loading (type B)), the resolved shear stress average is equal to only $81 \%$ of the maximal macroscopic shear stress. This means that the modified Schmid factor, $\tau / \Sigma$, is indeed equal to only 0.41 whereas the macroscopic Schmid factor, $\mathrm{T} / \Sigma$, is equal to 0.5 . In addition, in the grain with a [100] tensile axis, the computed modified Schmid factor is equal to only 0.255 instead of 0.408 (macroscopic Schmid factor). These modified Schmid factor values have to be taken into account when considering both single crystal and polycrystal fatigue limits. In numerous metals and alloys, cracks initiate along Persistent Slip Bands (PSBs) in which plastic slip intensively localizes. That is why the PSB formation shear stress threshold, $\tau_{\mathrm{PSB}}$, is sometimes used for evaluating high-cycle fatigue stress limits for single crystals and polycrystals [18]. If a PSB threshold value is measured using tests and observations carried 
out on single crystals (for example in copper, $\tau_{\mathrm{PSB}} \approx 28 \mathrm{MPa}[19]$ ), then in a polycrystal, PSBs and cracks would appear in the well-oriented grains if the local shear stress exceeds this value. Finally, it would give a tension-compression stress threshold value for the polycrystal of about: $\Sigma_{\mathrm{PSB}}=\tau_{\mathrm{PSB}} / \mathrm{f}_{\text {macro }}=2 \tau_{\mathrm{PSB}}$ if isotropic elasticity is considered. But, following our computations, the cubic elasticity affects the resolved shear stress value leading to a modified stress threshold value: $\Sigma_{\mathrm{PSB}} \approx \tau_{\mathrm{PSB}} / f_{\text {modif. }}$ For copper and austenite, the effect is non-negligible as: $\Sigma_{\mathrm{PSB}} \approx 2.4 \tau_{\mathrm{PSB}}$. This threshold is $20 \%$ higher than the previous which was obtained assuming that crystalline behavior is isotropic (homogeneous stress). This result should hold for cyclic tension-compression applied on copper or austenite polycrystals. For ferrite, the difference on the polycrystal threshold is about $+11 \%$. And, for aluminium, the difference is negligible. Similar evaluations can be carried out using the maximum value of the effective Schmid factor computed in a well-oriented grain considering all sets of neighbour grains with random orientations. In this case, a value of 0.5 can reached. But, these high values $(>0.47$ for example) are much rarer than it is predicted by the classical Schmid factor distribution (given in [6] for example).

The previous results are now discussed with respect to the numerous test results and observations carried out on copper polycrystals, which are reported in the literature. Polak et al. studied PSBs in copper polycrystals subjected to high-cycle fatigue [20]. Using TEM observations of bulk foils, they observed no PSB for a (maximal) tension-compression stress of $68 \mathrm{MPa}$. But, using SEM observations of the specimen surfaces, they observed PSBs at the same stress amplitude. For a stress of $54 \mathrm{MPa}$, they observed very rare PSBs. Such discrepancies between surface and bulk observations have been already reported by Mughrabi and Wang who observed both surface and bulk foils using TEM [21]. Using optical observations of the specimen surfaces, Mughrabi and Wang observed that $30 \%$ of the surface grains contain PSBs for a stress equal to $68 \mathrm{MPa}$. But, PSBs were very rare for a stress equal 
to $58 \mathrm{MPa}$. If the classical Schmid factor distribution given in [6] is used as well as the single grain PSB threshold $\left(\tau_{\mathrm{PSB}}=28 \mathrm{MPa}\right)$, then fractions of surface grains presenting PSBs of $30 \%$ and $85 \%$ can be deduced for macroscopic stress of respectively 58 and $68 \mathrm{MPa}$ (i.e. grains $\left.\mathrm{f}_{\text {macro }} \Sigma>\tau_{\text {PSB }}\right)$. Therefore the comparison between experimental data and predictions based on the reference Schmid factor gives strong discrepancies. It should be noticed that the Schmid modified factor obtained in a well-oriented grain with particular neighboring grain orientations could be considered instead of the mean value computed using all configuration results. For example, the maximum value could be considered (Table 2). But the corresponding configuration is rather rare (particular orientations of the neighbour grains) and its statistical influence should be small concerning microplasticity slip line observations. For a macroscopic tension-compression stress of $58 \mathrm{MPa}$, the predicted fraction of surface grains such as: $\tau>\tau_{\mathrm{PSB}}$ would in fact be very small (about $2 \%$ following [22]) whereas the classical Schmid factor distribution (neglecting crystalline elasticity anisotropy) would lead to a predicted fraction of about $30 \%$ (using the Schmid factor distribution given by Blöchwitz et al. [6]).

Following the previous references, the numbers of cycles to failure corresponding to these macroscopic stresses had orders of magnitude of $10^{6}-10^{7}$ cycles. Therefore these stresses could be considered as fatigue limits depending on the chosen critical number of cycles. Still concerning the polycrystal tension-compression fatigue limit, Winter et al. gave an experimental value of $70 \mathrm{MPa}$ [8] whereas they gave single crystal plateau shear stress equal to $27 \mathrm{MPa}$. This gives a fatigue limit ratio equal to $70 / 27=2.6$ which is once more higher than 2. The influence of the grain size is not taken into account in our computations concerning microplasticity. Following several observations reported in the literature, this hypothesis seems reasonable. Mughrabi and Wang showed that the grain size has a negligible effect on the the critical macroscopic stress for PSB formation at the polycrystal free surface and on the 
measured fractions of grains presenting PSBs (copper polycrystals, small applied strain, grain size range: ) [21]. Hessler [23] (copper) and Cugy and Galtier [24] (ferrite) showed that the grain size has a very reduced influence on the critical macroscopic stress for PSB formation. The mechanism of PSB formation in austenitic steels, predicted by Discrete Dislocation Dynamics and discussed in [25], could explain the independence of the resolved shear stress at the grain scale with respect to the grain scale.

The influence of loading conditions (shear, tension-compression, equibiaxial) is now discussed. Their respective effects are compared assuming that the same Tresca value is reached for each loading. For shear and tension-compression, the average resolved shear stresses are about the same. But, the average normal stress is much higher for a tensioncompression test. This corresponds to the classical explanation of the difference between the shear and tension-compression (Tresca stress) fatigue limits. It should nevertheless be noticed that non-negligible normal stresses can be obtained (18\% of the average shear stress). And, considering the orientations of neighboring grains giving the maximal normal stress amplitude, the computed normal stress is equal to $58.3 \%$ of the average shear stress. Concerning tension-compression or equibiaxial loading, the computed average and scatter values are close and do not indicate that the one or the other is more damaging. But, additional parameters should be considered for explaining more satisfactorily the fatigue differences between torsion, tension-compression, and equibiaxial test results. For example, type B planes are usually supposed to be more dangerous than type A ones. On the one hand, only type B planes (and intermediate ones) induce relief formation which can accelerate damage evolution. On the other hand, cyclic plastic slips are higher in surface type B slip bands or grains than in type A ones because of free surface effects [10,17]. Torsion is only concerned by type A planes, tension-compression by both type A and type B ones (and intermediate planes), and equibiaxial loading by type B only [17]. This partially explains why 
torsion is usually considered as less dangerous than tension-compression. On the contrary, the proportion of type B well-oriented grains at the free surface of a specimen is much higher for an equibiaxial test than for a tension-compression test. Therefore, a higher number of microcracks could appear and failure could therefore be accelerated for equibiaxial loadings. Neighboring grains can induce a high scatter in the stresses in grains with the same crystallographic orientation. This can explain, at least qualitatively, some observations taken from the literature. These observations concern metals and alloys presenting high elasticity anisotropy factors such as copper or austenic steels. As it was shown previously, for these materials the local resolved shear stress in well-oriented surface grains can vary between 0.61T and T (Table 9). Following the SEM observations of Man et al [7] on an austenitic steel polycrystal, some well-oriented surface grains present an "anomalous" microplasticity behavior. Their macroscopic Schmid factor are equal to about 0.5 and their corresponding slip vectors form an angle with respect to the free surface, $\alpha$, which is non-negligible. Nevertheless, no slip marking is visible on the surface of these grains. On the contrary, the majority of the surface grains (86\%) present visible slip markings even if their macroscopic Schmid factor and/or their angle between the corresponding slip vector and the free surface are smaller. Even if the corresponding angle is taken into account, the authors showed that there is no univocal relationship between the macroscopic Schmid factor and the plasticity induced relief. Similar SEM observations concerning nickel polycrystals (anisotropy factor a $\approx 2.5$ ) have been reported by Blochwitz et al. who considered as "anomalous", grains with a Schmid factor higher than 0.43 , an angle $\alpha$ for which $\sin (\alpha)$ was higher than 0.15 and nevertheless no slip marking [6]. In the corresponding experiments, the macroscopic plastic strains were respectively equal to $10^{-3}[7]$ and $5.10^{-4}$ [6]. In addition, several authors reported TEM observations of the dislocation microstructures of grains with the same tensile axis $[21,11]$. They showed that the dislocation microstructure could vary considerably among 
these grains (for example grains for which the tensile axis is parallel to the [-3 911 ] direction and the Schmid factor is equal to 0.45 [21]). In some of them, slip bands were observed but in the other ones none was visible using TEM. In these studies, copper polycrystals were used and macroscopic plastic strains were small (a few $10^{-4}$ ). The high computed scatter value induced by neighboring grain effects can partially explain these discrepancies: in some welloriented grains, the critical shear stress for slip band formation was reached, whereas in the other ones (with the same orientation) it was not because of particuler neighboring grain orientations. For quantitative comparisons, the minimal resolved shear stresses in welloriented surface grains (with a reference Schmid factor of 0.5) are computed for nickel, copper, and 316L. They are compared with the corresponding PSB formation critical shear stresses which have been measured using single crystals [22,27] or deduced from tests and observations performed on polycrystals [28] (Table 10). Complementary computations are carried out for nickel, using the crystalline elasticity coefficients given in [25]. For nickel, the computation can not explain the observed "anomalous" behavior whereas for copper the resolved shear stress in some well-oriented grains is close to the critical shear stress for PSBs formation but a bit higher. And, for the austenitic steel, the minimal resolved shear stress is lower than the corresponding PSB threshold. Therefore, the previous computations do not permit us to explain quantitatively all the observations reported for the three materials. Plasticity effects could not explain the discrepancy observed for nickel. For a given macroscopic stress of Table 10, used in the previous elastic computations, plastic deformation of the surrounding grains and matrix should lead to the formation of forward stresses in the grains which deform purely elastically (Kröner's inclusion approach [29]). Therefore, still for a given macroscopic stress, plasticity would not delay the plastic deformation in elastic grains. Of course, for a given macroscopic strain, the stresses in grains considered as elastically-deformed would be smaller with plasticity than without. In fact, the 
microstructures of the three polycrystals contain twins and grains with various sizes $[6,7,21]$.

Only a regular microstructure with similar grains is considered in our study in order to evaluate specifically the influence of random crystallographic orientations. Complementary work is therefore needed for evaluating the effect on the scatter induced by the heterogeneity of grain size and geometry.

\subsection{SHORT FATIGUE CRACK NUCLEATION AND EARLY PROPAGATION}

The stress scatter should affect short crack nucleation and propagation. It can be reasonably assumed that the number of cycles to nucleation of a short crack depends on the resolved shear stress in the considered well-oriented grain. The shear stress affects the plastic slip which can be either uniform in the well-oriented grain or localized in slip bands (for example Persistent Slip Bands) [21]. And the plastics slips are known to be the driving force for crack nucleation $[13,21]$. As mentionned before, our elastic computations do not permit us to evaluate the plastic slips. It can nevertheless be guessed that for small plastic strains, the effect of the resolved shear stress scatter induced by neighboring grain effects on the crack nucleation should be large. On the one hand, the resolved shear stress is the driving force for plastic slip and a small variation on the resolved shear stress could induce a large variation of the plastic slip in the low strain cycling of well-oriented single crystals [21]. On the other hand, following the Wöhler curve plotted by Kettunen for copper single crystals, a resolved shear stress variation of a few MPa induces a lifetime variation of one order of magnitude in the high-cycle regime (lifetime $\sim 10^{6}$ cycles) [30]. Finally, the scatter in the normal stress to the crack plane can influence the crack propagation rates in addition to the resolved shear stress scatter.

Crystalline elasticity anisotropy can therefore increase both short crack initiation and propagation rate scatter, especially for metals presenting high anisotropy factors (copper, 
austenite, ferrite, and nickel). But, quite no scatter is predicted for aluminium and other metals presenting low anisotropy factors (tungstène). Lankford et al. [31] reported that the crack propagation rates measured for two different cracks in an aluminium polycrystal can vary by a factor 3 even if the crack lengths are the same (equal to about one grain size). Either the corresponding grains have different Schmid factors which can explain this discrepancy or the Schmid factors are close as it should be the case for well-oriented grains. If the Schmid factors and normal stresses are close, the scatter can not be explained by neighbor effects induced by crystalline elasticity anisotropy (negligible for aluminium). But, it could be due crystalline plasticity anisotropy. In fact, even if the applied stress during their test is a bit smaller than the conventional flow stress, plastic glide occurs in some grains which are more or less plastically deformed depending on their Schmid factor [11-13]. The stress field is therefore heterogeneous and neighbor effects occur because of crystalline plasticity anisotropy instead of elasticity anisotropy.

It should be noticed that the given scatter parameters (Tables 2-9, Fig. 7) are computed using the grain average values (60 grains for each crystallographic orientation or phase, metal, and loading condition). Therefore, the given standard deviations are smaller than the total intra-orientation standard deviations which can be computed for the given crystallographic orientation. These total intra-orientation standard deviations are computed using the whole stress fields in the grains with the same orientation. In fact, in each of these grains, the stress field is heterogeneous, particularly near grain boundaries and triple points. A numerical integration is carried out using the stress component values obtained at each Gauss point of each grain (of the same orientation). As an example, the total intra-orientation tensile stress standard deviation obtained in type B surface grains of an austenitic polycrystal is evaluated. Its normalized value is equal to $14.2 \%$ but the standard deviation computed using the grain average stress values is equal to only $8 \%$ (Table 5 ). These are normalized standard deviations 
(using the orientation average values for normalization). Therefore, the standard deviation using the average grain values represents a little more than one half of the total intraorientation standard deviation. This shows that the intragrain scatter is important too (obtained for given crystallographic orientations of the neighboring grains). These local stress gradients could affect the damage mechanisms too (intergranular crack initiation). The effect of grain boundaries on stress and strain gradients were recently studied by Diard et al. considering crystalline viscoplasticity but neglecting crystalline elasticity [32].

As a first attempt, crystalline (visco)plasticity is neglected in our Finite Element computations. Even if the macroscopic (visco)plastic strain is very small, experimental observations showed that (visco)plastic glide takes place in some grains, particularly in welloriented grains [20,21]. Recent numerical studies gave evaluations of the scatter parameters induced by crystalline viscoplasticity anisotropy [13,33]. But all these studies neglected the influence of crystalline elasticity which probably affects scatter when small macroscopic strains are applied as it is the case for High-Cycle Fatigue. Using the same approach, work is in progress for evaluating the influence of both crystalline elasticity and plasticity anisotropies on scatter in mechanical stress fields and crack nucleation/micropropagation in surface grains. The plastic slips, which are often considered as the driving force for crack nucleation, could be computed and used in crack nucleation criteria as described in [13].

\section{Conclusions}

Monte Carlo Finite Element computations are carried out for evaluating the effect of crystalline elasticity and neighboring grain orientations on the stress state in well-oriented type A/B grains. These grains present indeed a high resolved shear on one of their slip system and are prone to be crack nucleation sites. Stress states in either type A/B well-oriented grains or $<100>$ grains have been studied. The considered grain is located at the free surface of a 3D 
aggregate which is embedded in a matrix. The crystallographic orientations of the neighboring grains are random. The influence of elasticity anisotropy (aluminium, ferrite, copper, austenite) and loading condition (tension-compression, shear, equibiaxial loading) are extensively studied. For each orientation, metal, and loading condition, 60 Finite Element computations are carried out, using 60 sets of random orientations of the neighboring grains. Average and scatter values are given for both shear stress and normal stress computed on the well-oriented slip system. For usual metals such as copper and austenite subjected to tensioncompression, average resolved shear stress and normal stress are different from macroscopic stresses (giving ratios with respect to the macroscopic values of respectively 0.81 and 1.04). The modified Schmid factor is defined as the ratio between the local resolved shear stress and the macroscopic tensile stress. It is equal to only 0.41 which is considerably smaller than the classical 0.5 value (isotropic cubic elasticity). The (gaussian) scatter parameter of the resolved shear stress is about $\pm 22 \%$ (three times the standard deviation divided by the average value). The scatter parameter of normal stress is even higher (about $\pm 38 \%$ ). Results are given for numerous metals with various anisotropy coefficients and loading conditions. Concentration effects due to very particular sets of neighboring grain orientations are evaluated giving upper and lower values with respect to the random computation results. In addition, 3D effects are discussed considering the neighboring grain layer under the considered grain. Finally, using classical nucleation or propagation models, the consequences of the stress-strain scatter on the local damage kinetics is discussed. These results could help to better understand the crack nucleation mechanisms and the experimental surface observations of cyclic microplasticity (dislocation microstructures, slip activations), and damage nucleation.

Acknowledgments. The authors thank CEA (DSOE and DSNI) and IRSN for financial support. H. Mughrabi is gratefully acknowledged for interesting discussion. 


\section{References}

[1] K. J. Miller. The short crack problem. Fatigue of Engineering Materials and Structures 5 (1982) 223-232.

[2] J. Lankford. The growth of small fatigue cracks in 7075-T6 Aluminium. Fatigue of Engineering Materials and Structures 5 (1982) 233-248.

[3] M. Mineur, P. Villechaise, J. Mendez. Influence of the crystalline texture on the fatigue behavior of a 316L austenitic steel. Material Science and Engineering A286 (2000) 257-268.

[4] F. Bastenaire: ASTM STP 511 (1972).

[5] M. Mineur. Conditions locales d'amorçage des fissures de fatigue dans un acier inoxydable de type 316L : aspects cristallographiques (EBSD). Thèse de l’Université de Poitiers (2000).

[6] C. Blochwitz, J. Brechbühl, W. Tirschler. Analysis of activated slip systems in fatigued nickel polycrystals using the EBSD-technique in the scanning electron microscope. Materials Science Engineering A210 (1996) 42-47.

[7] J. Man, K. Obrtlik, C. Blochwitz, J. Polak. Atomic force microscopy of surface relief in individual grains of fatigued 316L austenitic stainless steel. Acta Materialia 50 (2002) 37673780.

[8] A. T. Winter, O. B. Pedersen, K. V. Rasmussen. Dislocation microstructures in fatigued copper polycrystals. Acta Metallurgica 29 (1981) 735-748.

[9] M. Kato, S. Onaka, T. Mori, T. Mura. Statistical consideration of plastic strain accumulation in cyclic deformation and fatigue crack initiation. Scripta Metallurgica 18 (1984) 1323-1326.

[10] M. Sauzay, P. Gilormini. Influence of surface effects on fatigue microcracks nucleation. Theoretical and Applied Fracture Mechanics 38 (2002) 53-62. 
[11] T. Hoshide, D. F. Socie. Crack nucleation and growth modeling in biaxial fatigue. Engineering Fracture Mechanics 29 (1988) 287-299.

[12] G. Cailletaud, V. Doquet, A. Pineau. Cyclic multiaxial behaviour of an austenitic stainless steel: microstructural observations and micromechanical modelling. In K. Kussmaul, D. McDiarmid and D. Socie (eds) Fatigue under biaxial and multiaxial loading. Mechanical Engineering Publications. London (1991) pp. 131-149.

[13] V. P. Bennett, D. L. McDowell. Polycrystal orientation distribution effects on microslip in high cycle fatigue. International Journal of Fatigue 25 (2003) 27-39.

[14] N. J. Teng, T. H. Lin. Elastic anisotropy effect of crystals on polycrystal fatigue crack initiation. Transactions of ASME 117 (1995) 470-477.

[15] S. Pommier. 'Arching' effect in elastic polycrystals: implications for the variability of fatigue lives. Fatigue of Engineering Materials and Structures 25 (2002) 331-348.

[16] F. A. Mc Clintock, A. S. Argon. Mechanical behaviour of materials. Addison-Wesley Publishing Company (1966).

[17] M. Sauzay, P. Gilormini. Surface and cyclic microplasticity. Fatigue of Engineering Materials and Structures 23 (2000) 573-580.

[18] H. Mughrabi. On the life-controlling microstructural fatigue mechanisms in ductile metals and alloys in the gigacycle regime. Fatigue of Engineering Materials and Structures 22 (1999) 633-641.

[19] J. M. Finney, C. Laird. Strain localization in cyclic deformation of copper single crystals. The Philosophical Magazine 31 (1975) 339-366.

[20] J. Polak, K. Obrtlik, M. Hajek, A. Vasek. Cyclic stress-strain response of polycrystalline copper in a wide range of plastic strain amplitudes. Materials Science and Engineering A286 (2000) 257-268. 
[21] H. Mughrabi, R. Wang. Cyclic stress-strain response and high-cycle fatigue behaviour of copper polycrystals. In P. Lukas and J. Polak (eds.) Basic mechanisms in fatigue of metals. Elsevier. Amsterdam (1988).

[22] M. Sauzay. Cubic elasticity, microplasticity and high-cycle fatigue crack nucleation in polycrystals. In W. S. Johnson, D. L. McDowell, J. C. Newman and A. Saxena (eds) Fatigue2006. Elsevier. Oxford (2006).

[23] W. Hessler. Wechselverformungsverhalten von vielkristallinem $\mathrm{Cu}$ im bereich hoher Lastwechselzahlen. PhD-Thesis, University of Vienna (1981)

[24] P. Cugy, A. Galtier. Microplasticity and temperature increase in low carbon steels. In A. F. Blom (ed.). Fatigue 2002. Emas. Cradley Heath (2002).

[25] C. Déprés, C.F. Robertson, M.C. Fivel. Crack initiation in fatigue: experiments a,d threedimensional dislocation simulations. Materials Science and Engineering A387-389 (2004) 288-291.

[26] H. B. Huntington. The elastic constants of crystals. In F. Seitz, D. Turnbull (eds.) Solid State Physics, vol. 7. Academic Press Incorporation Publishers. New-York (1958) pp. 214351.

[27] K. Mecke, C. Blochwitz. Saturation dislocation structures in cyclically deformed nickel single crystals of different orientations. Crystal Research \& Technology 17 (1982) 743-758.

[28] Y. Li, C. Laird. Cyclic response and dislocation structures of AISI stainless steel. Part 2: polycrystals fatigued at intermediate amplitude. Materials Science and Engineering A186 (1994) 87-103.

[29] E. Kröner. On the plastic deformation of polycrystals. Acta Metallurgica 9 (1961) 151161.

[30] P. O. Kettunen. Fatigue hardening of copper single crystals at low stress amplitudes. Acta Metallurgica 15 (1967) 1275-1286. 
[31] J. Lankford, D. L. Davidson, K. S. Chan. The influence of crack tip plasticity in the growth of small fatigue cracks. Metallurgical Transactions A 15 (1984) 1579-1588.

[32] O. Diard, S. Leclercq, G. Rousselier, G. Cailletaud. Evaluation of finite element based analysis of 3D multicrystalline aggregates plasticity. Application to crystal plasticity model identification and the study of stress and strain fields near grain boundaries. International Journal of Plasticity 21 (2005) 691-722.

[33] R. A. Lebensohn, Y. Liu, P. Ponte Castaneda. On the accuracy of the self-consistent approximation for polycrystals: comparison with full-field numerical simulations. Acta Materialia 52 (2004) 5347-5361. 


\section{List of tables}

Table 1: elastic constants of the studied crystals (GPa) (cubic elasticity) [16,26], corresponding anisotropy coefficient, and macroscopic elasticity coefficients (isotropic elasticity).

Table 2: mean, maximum, minimum values and scatter of the resolved shear stress (type B; $n=1 / \sqrt{ } 3(1,1,1)$ and $m=1 / \sqrt{ } 2(1,0,-1)$ for FCC metals; $n=1 / \sqrt{ } 2(1,0,-1)$ and $m=1 / \sqrt{ } 3(1,1,1)$ for the BCC metal).

Table 3: mean, maximum, minimum values and scatter of the normal stress (type B; $n=1 / \sqrt{ } 3(1,1,1)$ and $m=1 / \sqrt{ } 2(1,0,-1)$ for FCC metals; $n=1 / \sqrt{ } 2(1,0,-1)$ and $m=1 / \sqrt{ } 3(1,1,1)$ for the BCC metal).

Table 4: coefficients of the fitted polynomials of curves displayed on Figures 3 and 7. The polynomials are defined by: $\mathrm{C}_{0}+\mathrm{C}_{1} \mathrm{a}+\mathrm{C}_{2} \mathrm{a}^{2}$.

Table 5: stress components in a well-oriented type B grain. Tension-compression, austenite. Grain average values.

Table 6: comparison of scatter of resolved shear stress in the middle grain for different grain orientations (case of austenite, tension-compression). 
Table 7: comparison of scatter of normal stress in the middle grain for different grain orientations (case of austenite, tension-compression).

Table 8: influence of the neighboring grain sub-layer (Finite Element computation results obtained using either the aggregate mesh depicted in Fig. 2 b) or in Fig 2 d)). Tensioncompression, austenite, $<111>$ middle grain (tensile axis parallel to the $<111>$ axis of this grain).

Table 9: comparison between computations carried out on 60 random microstructures and simplified configurations (inclusion, hard and soft grains; case of austenite). Resolved shear stresses for a macroscopic tensile stress equal to $300 \mathrm{MPa}$.

Table 10: minimum resolved shear stresses computed in well-oriented surface grains (macroscopic Schmid factor of 0.5) and comparison with the critical shear stresses for PSB formation in single crystals (austenite [28], nickel [7,6] and copper [21]). Possible explanation of the "anomalous" behavior of some well-oriented surface grains [7,6,21]. Table 2 is used for this purpose as well as complementary computations on nickel polycrystal. 


\section{Tables}

\begin{tabular}{|c|c|c|c|l|l|l|c|}
\hline & $\mathrm{C}_{11}$ & $\mathrm{C}_{12}$ & $\mathrm{C}_{44}$ & $=\mu_{\max } / \mu_{\min }$ & $\mathrm{E}_{\max } / \mathrm{E}_{\min }$ & $\mathrm{E}$ & $v$ \\
\hline $\mathrm{Al}$ & 107 & 60.8 & 28.3 & 1.22 & 1.17 & 70. & 0.34 \\
\hline $\mathrm{Fe} \alpha$ & 247.7 & 144.6 & 118 & 2.29 & 2.5 & 200. & 0.33 \\
\hline $\mathrm{Cu}$ & 170 & 124 & 75 & 3.26 & 3. & 130. & 0.35 \\
\hline $\mathrm{Fe} \gamma$ & 197.5 & 125 & 122 & 3.36 & 2.96 & 200. & 0.33 \\
\hline
\end{tabular}

Table 1: elastic constants of the studied crystals (GPa) (cubic elasticity) [16,26], corresponding anisotropy coefficient, and macroscopic elasticity coefficients (isotropic elasticity).

\begin{tabular}{|c|c|c|c|c|c|c|}
\hline & $a$ & Mean value & $\begin{array}{c}\text { Maximum } \\
\text { value }\end{array}$ & $\begin{array}{c}\text { Minimum } \\
\text { value }\end{array}$ & $3 \Delta \tau / \tau_{\mathrm{av}}(\%)$ & $\begin{array}{c}\left(\tau_{\max }-\tau_{\min }\right) / \\
\left(2 \tau_{\mathrm{av}}\right)(\%)\end{array}$ \\
\hline $\mathrm{Al}$ & 1.22 & 0.97 & 1. & 0.95 & 3.7 & 2.5 \\
\hline $\mathrm{Fe} \alpha$ & 2.29 & 0.92 & 1.03 & 0.83 & 15.3 & 11. \\
\hline $\mathrm{Cu}$ & 3.26 & 0.82 & 0.94 & 0.69 & 21.1 & 15.3 \\
\hline $\mathrm{Fe} \gamma$ & 3.36 & 0.81 & 0.94 & 0.68 & 22.2 & 16.2 \\
\hline
\end{tabular}

Table 2: mean, maximum, minimum values and scatter of the resolved shear stress (type B; $n=1 / \sqrt{ } 3(1,1,1)$ and $m=1 / \sqrt{ } 2(1,0,-1)$ for FCC metals; $n=1 / \sqrt{ } 2(1,0,-1)$ and $m=1 / \sqrt{ } 3(1,1,1)$ for the BCC metal).

\begin{tabular}{|c|c|c|c|c|c|c|}
\hline & $a$ & Mean value & $\begin{array}{c}\text { Maximum } \\
\text { value }\end{array}$ & $\begin{array}{c}\text { Minimum } \\
\text { value }\end{array}$ & $\begin{array}{c}3 \Delta \sigma / \sigma_{\mathrm{av}} \\
(\%)\end{array}$ & $\begin{array}{c}\left(\sigma_{\max }-\sigma_{\min }\right) \\
/\left(2 \sigma_{\text {av }}\right) \\
(\%)\end{array}$ \\
\hline $\mathrm{Al}$ & 1.22 & 1.01 & 1.06 & 0.95 & 6.8 & 5.4 \\
\hline $\mathrm{Fe} \alpha$ & 2.29 & 1.01 & 1.19 & 0.81 & 27.9 & 18.6 \\
\hline $\mathrm{Cu}$ & 3.26 & 1.04 & 1.34 & 0.73 & 39. & 29.5 \\
\hline $\mathrm{Fe} \gamma$ & 3.36 & 1.04 & 1.33 & 0.74 & 38. & 28.5 \\
\hline
\end{tabular}

Table 3: mean, maximum, minimum values and scatter of the normal stress (type B; $n=1 / \sqrt{ } 3(1,1,1)$ and $m=1 / \sqrt{ } 2(1,0,-1)$ for FCC metals; $n=1 / \sqrt{ } 2(1,0,-1)$ and $m=1 / \sqrt{ } 3(1,1,1)$ for the BCC metal). 


\begin{tabular}{|c|c|c|c|}
\hline & $\mathrm{C}_{0}$ & $\mathrm{C}_{1}$ & $\mathrm{C}_{2}$ \\
\hline$\tau_{\mathrm{av}}$ & 1.01 & -0.002 & -0.0171 \\
\hline$\sigma_{\mathrm{av}}$ & 1. & 0. & 0. \\
\hline 3 & -0.1692 & 0.1955 & -0.0238 \\
$\Delta \tau / \tau_{\mathrm{av}}$ & & & \\
\hline 3 & -0.327 & 0.3806 & -0.0501 \\
$\Delta \sigma / \sigma_{\mathrm{av}}$ & & & \\
\hline
\end{tabular}

Table 4: coefficients of the fitted polynomials of curves displayed on Figures 3 and 7. The polynomials are defined by: $\mathrm{C}_{0}+\mathrm{C}_{1} \mathrm{a}+\mathrm{C}_{2} \mathrm{a}^{2}$.

\begin{tabular}{|l|l|l|l|l|l|}
\hline & $\begin{array}{l}\text { Average } \\
(\%)\end{array}$ & $\begin{array}{l}\text { Maximum } \\
(\%)\end{array}$ & $\begin{array}{l}\text { Minimum } \\
(\%)\end{array}$ & $\begin{array}{l}\text { 3SD/Average } \\
(\%)\end{array}$ & $\begin{array}{l}\text { (Max-Min)/ } \\
\text { 2Average (\%) }\end{array}$ \\
\hline$\sigma_{\mathrm{xx}} /<\sigma_{\mathrm{xx}}>$ & 100. & 116.6 & 80.6 & 24.1 & 18. \\
\hline$\sigma_{\mathrm{xy}} /<\sigma_{\mathrm{xx}}>$ & 15.3 & 21.7 & 8.5 & 52.3 & 43.2 \\
\hline$\sigma_{\mathrm{yy}} /<\sigma_{\mathrm{xx}}>$ & -9.1 & 2.9 & -23.9 & -233. & -147. \\
\hline$\sigma_{\mathrm{zz}} /<\sigma_{\mathrm{xx}}>$ & 9.7 & 21.6 & -2.12 & 172. & 122. \\
\hline
\end{tabular}

Table 5: stress components in a well-oriented type B grain. Tension-compression, austenite. Grain average values.

\begin{tabular}{|l|c|}
\hline \multicolumn{1}{|c|}{ Type of loading } & $3 \Delta \tau / \tau_{\mathrm{av}}(\%)$ \\
\hline Type A & 15.0 \\
\hline Type B & 22.2 \\
\hline Tensile load along [100] & 31.1 \\
\hline
\end{tabular}

Table 6: comparison of scatter of resolved shear stress in the middle grain for different grain orientations (case of austenite, tension-compression).

\begin{tabular}{|l|c|}
\hline \multicolumn{1}{|c|}{ Type of loading } & $3 \Delta \sigma / \sigma_{\mathrm{av}}(\%)$ \\
\hline Type A & 33.4 \\
\hline Type B & 38. \\
\hline Tensile load along [100] & 26.5 \\
\hline \hline
\end{tabular}

Table 7: comparison of scatter of normal stress in the middle grain for different grain orientations (case of austenite, tension-compression). 


\begin{tabular}{|l|l|l|l|}
\hline $\begin{array}{l}\text { Grain } \\
\text { sub-layer }\end{array}$ & $\begin{array}{l}\text { Mean value } \\
\sigma_{\mathrm{xx}, \mathrm{av}}\end{array}$ & $3 \Delta \sigma_{\mathrm{xx}} / \sigma_{\mathrm{xx}, \mathrm{av}}(\%)$ & $\begin{array}{l}\left(\sigma_{\mathrm{xx}, \max }-\sigma_{\mathrm{xx}, \min }\right) / \\
\left(2 \sigma_{\mathrm{xx}, \mathrm{av}}\right)(\%)\end{array}$ \\
\hline without & 1.004 & 21.0 & 15.9 \\
\hline with & 1.004 & 21.2 & 16.2 \\
\hline
\end{tabular}

Table 8: influence of the neighboring grain sub-layer (Finite Element computation results obtained using either the aggregate mesh depicted in Fig. 2 b) or in Fig 2 d)). Tensioncompression, austenite, $<111>$ middle grain (tensile axis parallel to the $<111>$ axis of this grain).

\begin{tabular}{|c|c|c|}
\cline { 2 - 3 } \multicolumn{1}{c|}{} & $\begin{array}{c}\text { Computations on } \\
60 \text { microstructures }\end{array}$ & $\begin{array}{c}\text { Simplified } \\
\text { configurations }\end{array}$ \\
\hline $\begin{array}{c}\text { Mean value } \\
(\mathrm{MPa})\end{array}$ & 121.1 & 123.4 \\
\hline $\begin{array}{c}\text { Maximum } \\
\text { value }(\mathrm{MPa})\end{array}$ & 141.0 & 149.0 \\
\hline $\begin{array}{c}\text { Minimum } \\
\text { value }(\mathrm{MPa})\end{array}$ & 101.7 & 91.6 \\
\hline
\end{tabular}

Table 9: comparison between computations carried out on 60 random microstructures and simplified configurations (inclusion, hard and soft grains; case of austenite). Resolved shear stresses for a macroscopic tensile stress equal to $300 \mathrm{MPa}$.

\begin{tabular}{|l|l|l|l|l|}
\hline & $\begin{array}{l}\text { Remote tension- } \\
\text { compression } \\
\text { stress (MPa) }\end{array}$ & $\begin{array}{l}\text { Minimal resolved } \\
\text { shear stress } \\
(\mathrm{MPa})\end{array}$ & $\begin{array}{l}\text { Critical shear } \\
\text { stress for PSB } \\
\text { formation (MPa) }\end{array}$ & $\begin{array}{l}\text { Macroscopic } \\
\text { plastic strain } \\
\left(10^{-3}\right)\end{array}$ \\
\hline Austenite $[10,24]$ & 230. & 79. & $90 .-105$. & 1. \\
\hline Nickel $[9,23]$ & 180. & 74. & 50. & 0.5 \\
\hline Copper $[21,19]$ & 91. & 31. & 28. & 0.3 \\
\hline
\end{tabular}

Table 10: minimum resolved sheares stress computed in well-oriented surface grains (macroscopic Schmid factor of 0.5) and comparison with the critical shear stresses for PSB formation in single crystals (austenite [28], nickel [7,6] and copper [21]). Possible explanation of the "anomalous" behavior of some well-oriented surface grains [7,6,21]. Table 2 is used for this purpose as well as complementary computations on nickel polycrystal. 


\section{List of Figures}

Fig. 1. a) Possible slip systems in a surface well-oriented grain; b) type A and type B facets.

Fig. 2. a) Global mesh of the matrix containing the surface aggregate. Displacements are prescribed at the vertical sides depending on the loading condition (tension-compression, shear, equibiaxial loading). The two horizontal sides are traction free; b) mesh of a surface aggregate (the middle grain has a given crystallographic orientation but the surrounding grains have random orientations); c) mesh of one grain; d) mesh of an aggregate including a subsurface neighboring grain layer (there are 13 neighboring grains instead of 6 in the aggregate depicted in Fig. 2 d)).

Fig. 3. Variation of the normalized stresses depending on the elasticity anisotropy factor, a. Resolved shear stress and normal stress. Well-oriented type B grain, tension-compression.

Fig. 4. Resolved shear stress scatter. Austenite, well-oriented type B grain, tensioncompression. The resolved shear stress is averaged on the whole grain for each microstructure corresponding to one particular set of random orientations of the neighboring grains. The macroscopic tensile stress is equal to $300 \mathrm{MPa}$.

Fig. 5. Normal stress scatter. Austenite, well-oriented type B grain, tension-compression. The resolved shear stress is averaged on the whole grain for each microstructure corresponding to one particular set of random orientations of the neighboring grains. The macroscopic tensioncompression stress is equal to $300 \mathrm{MPa}$. 
Fig. 6. Cumulated probability of the resolved shear stress. Austenite, well-oriented type B grain, tension-compression. The macroscopic tension-compression stress is equal to $300 \mathrm{MPa}$.

Fig. 7. Variation of the standard deviation parameters depending on the elasticity anisotropy factor, a. Resolved shear stress and normal stress. Austenite, well-oriented type B grain, tension-compression.

Fig. 8. Simplified configuration of surface neighboring grains leading to the maximal resolved shear stress in the middle well-oriented type B grain (number 1). Grains 3, 4 and 6, 7 are oriented along [100] (soft grains low equivalent Young modulus), whereas grains 2 and 5 are oriented along [111] (hard grains with high equivalent Young modulus). Tensioncompression. 


\section{Figures}

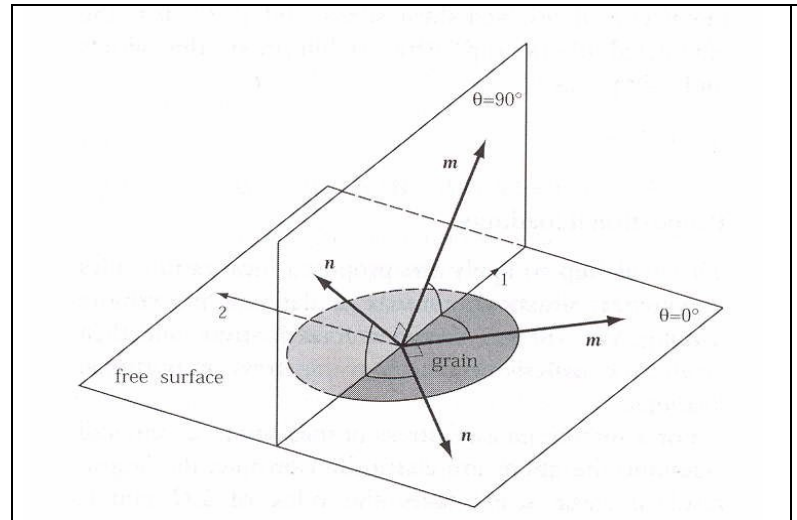

a)

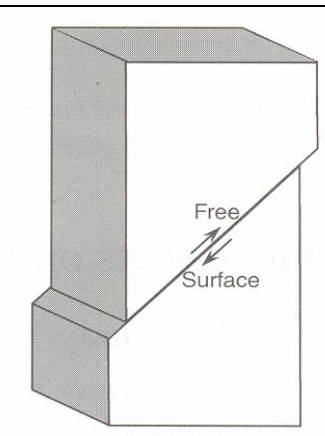

(a) type A

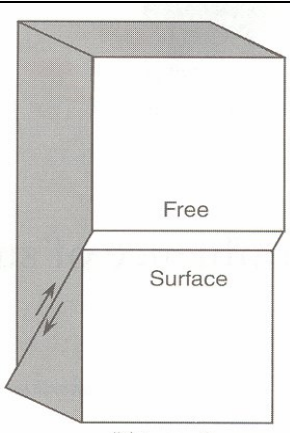

(b) type B

b)

Fig. 1. a) Possible slip systems in a surface well-oriented grain; b) type A and type B facets. 


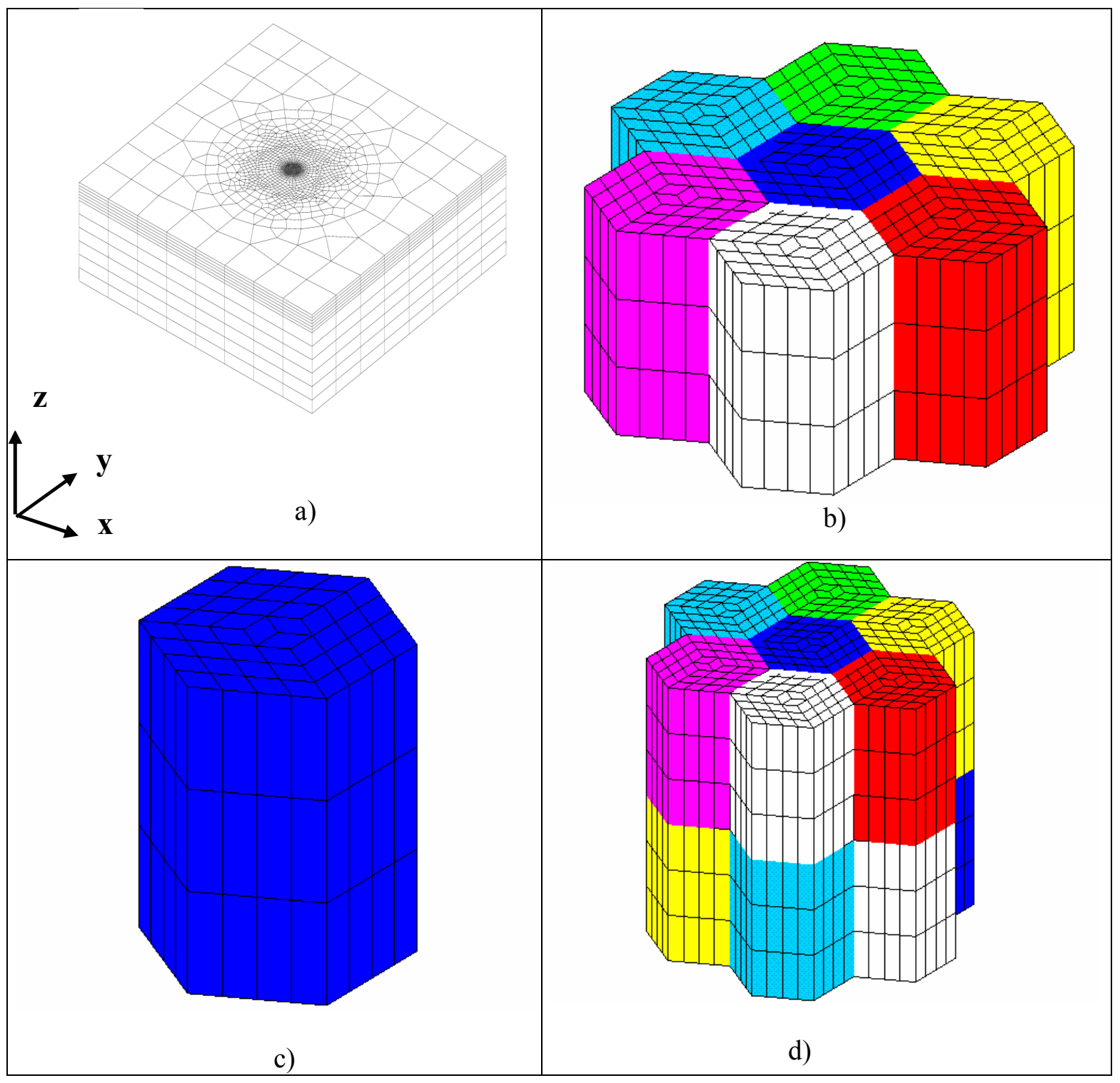

Fig. 2. a) Global mesh of the matrix containing the surface aggregate. Displacements are prescribed at the vertical sides depending on the loading condition (tension-compression, shear, equibiaxial loading). The two horizontal sides are traction free; b) mesh of a surface aggregate (the middle grain has a given crystallographic orientation but the surrounding grains have random orientations); c) mesh of one grain; d) mesh of an aggregate including a subsurface neighboring grain layer (there are 13 neighboring grains instead of 6 in the aggregate depicted in Fig. 2 d)). 


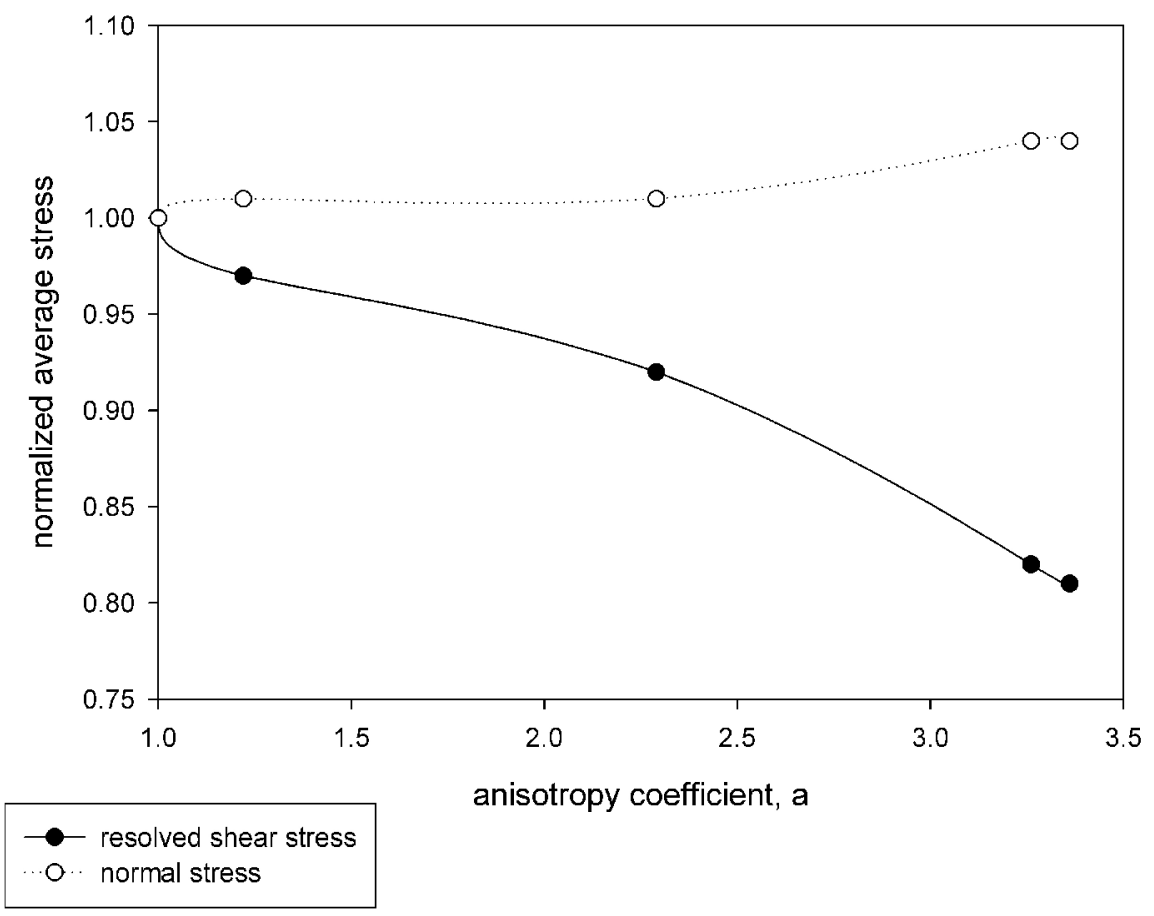

Fig. 3. Variation of the normalized stresses depending on the elasticity anisotropy factor, a. Resolved shear stress and normal stress. Well-oriented type B grain, tension-compression.

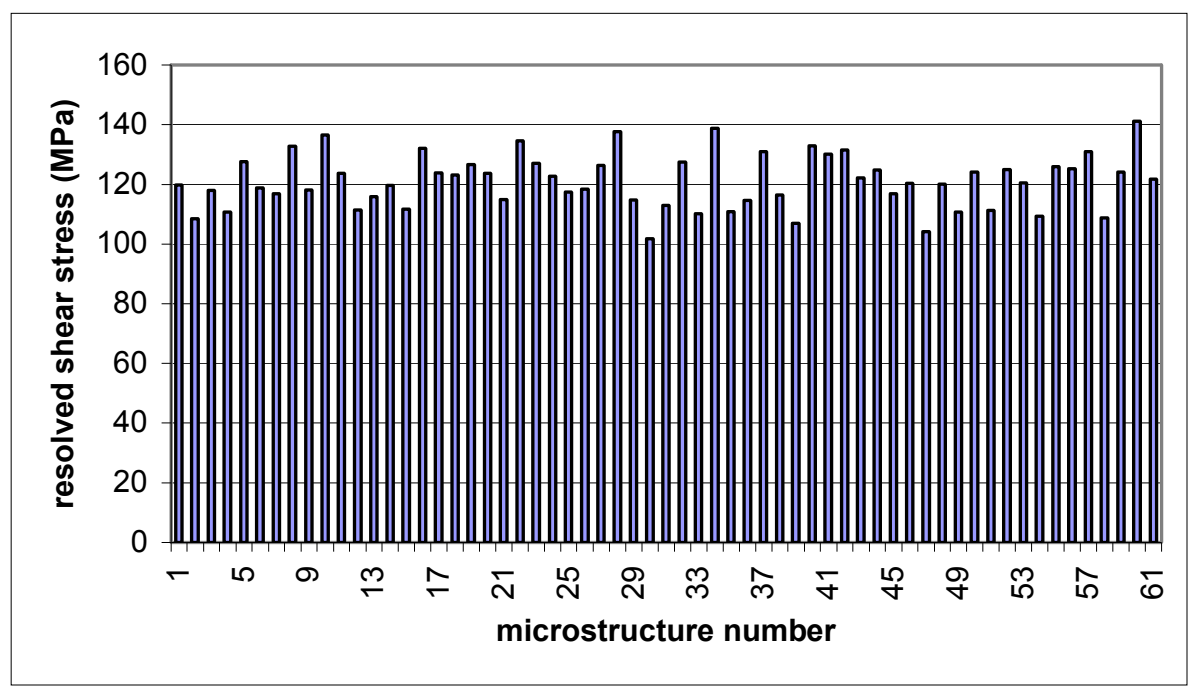

Fig. 4. Resolved shear stress scatter. Austenite, well-oriented type B grain, tensioncompression. The resolved shear stress is averaged on the whole grain for each microstructure corresponding to one particular set of random orientations of the neighboring grains. The macroscopic tension-compression stress amplitude is equal to $300 \mathrm{MPa}$. 


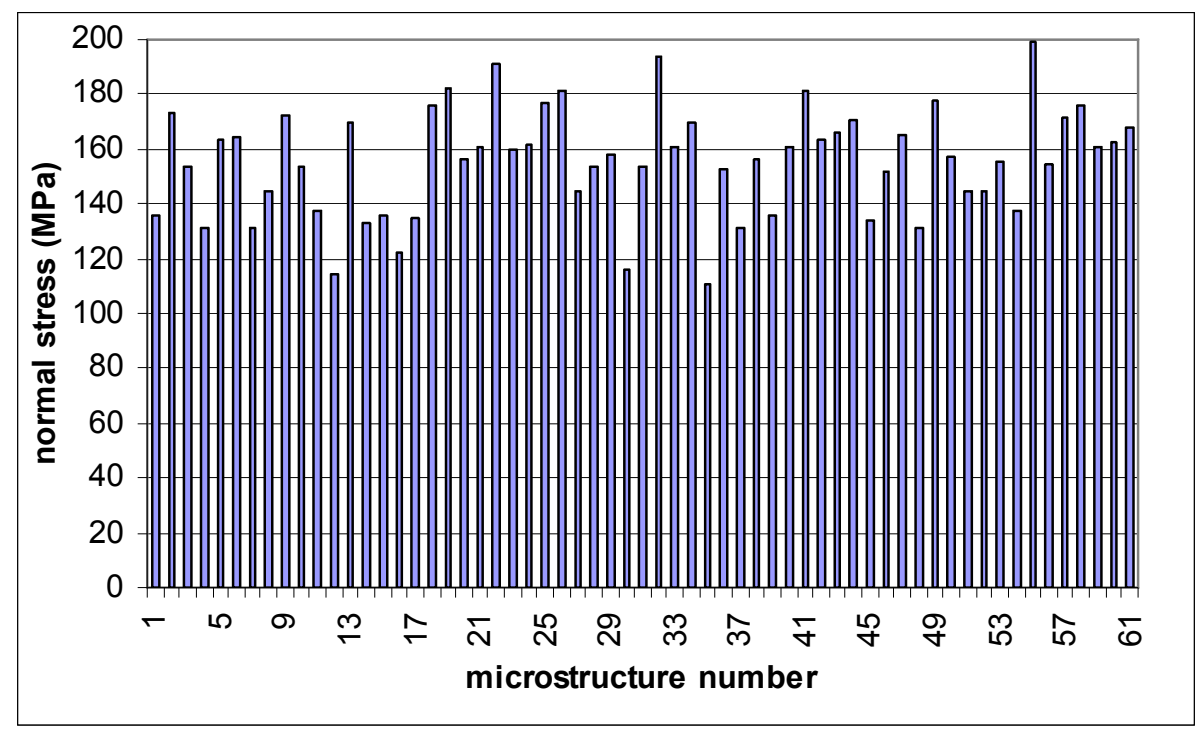

Fig. 5. Normal stress scatter. Austenite, well-oriented type B grain, tension-compression. The resolved shear stress is averaged on the whole grain for each microstructure corresponding to one particular set of random orientations of the neighboring grains. The macroscopic tension compression stress amplitude is equal to $300 \mathrm{MPa}$.

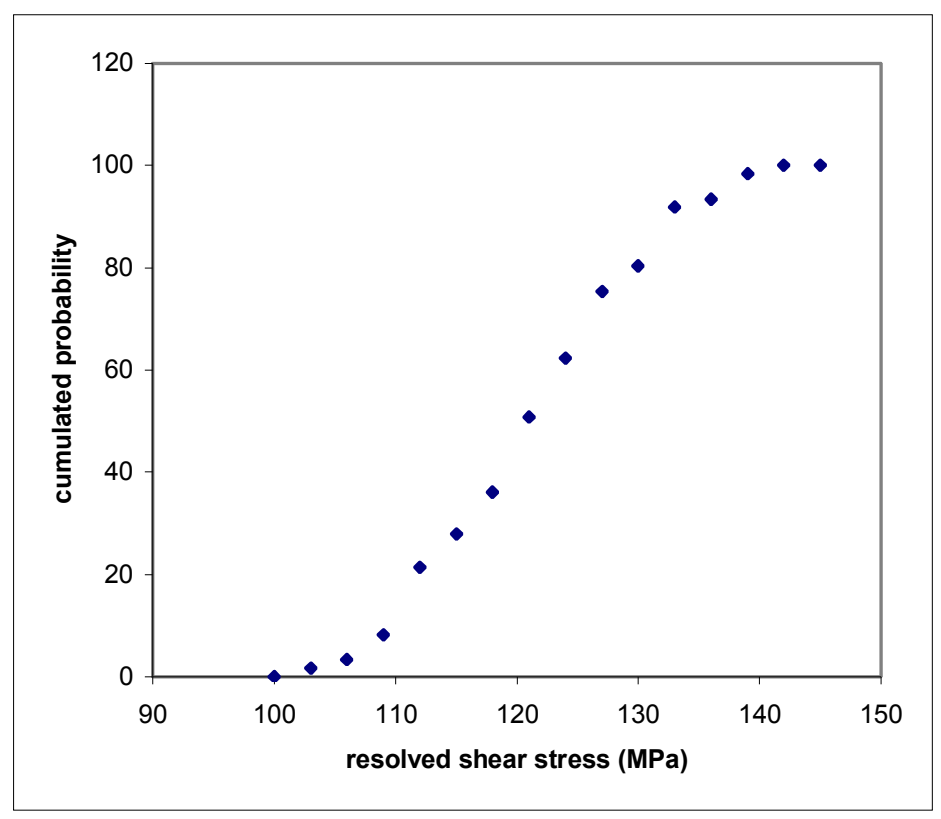

Fig. 6. Cumulated probability of the resolved shear stress. Austenite, well-oriented type B grain, tension-compression. The macroscopic tension-compression stress amplitude is equal to $300 \mathrm{MPa}$. 


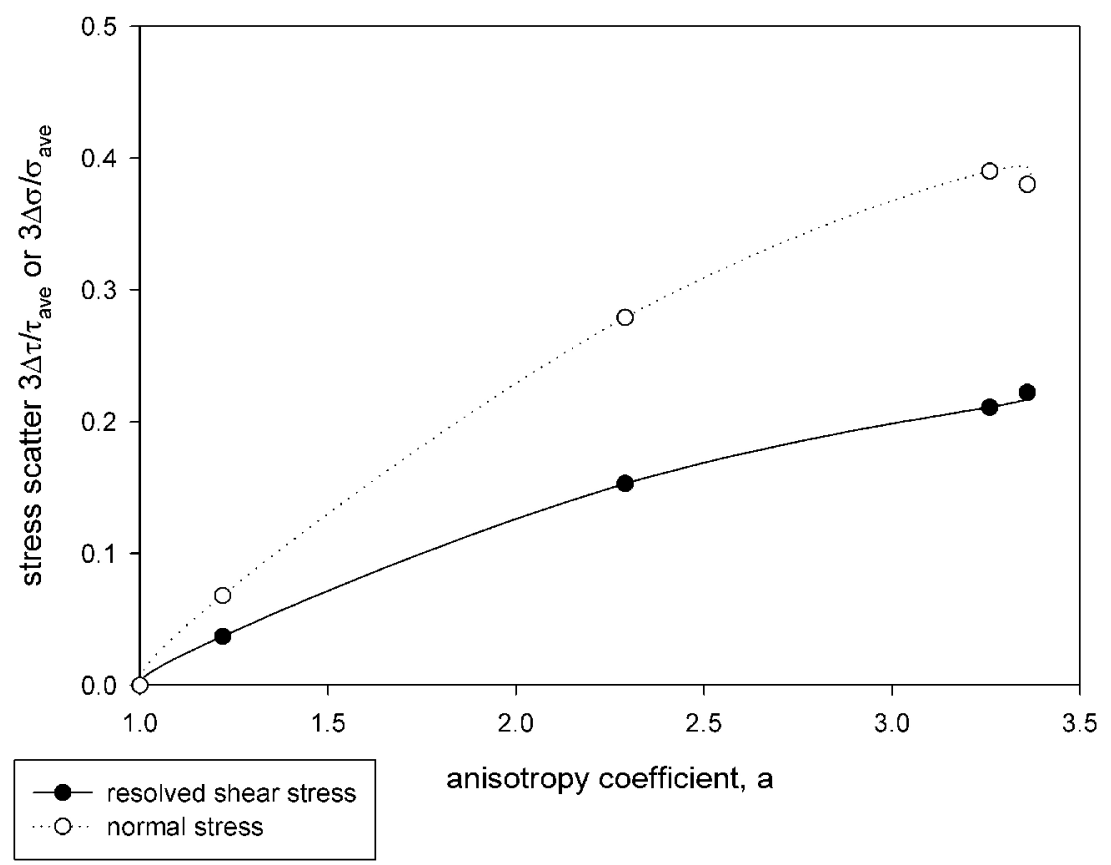

Fig. 7. Variation of the standard deviation parameters depending on the elasticity anisotropy factor, a. Resolved shear stress and normal stress. Austenite, well-oriented type B grain, tension-compression.

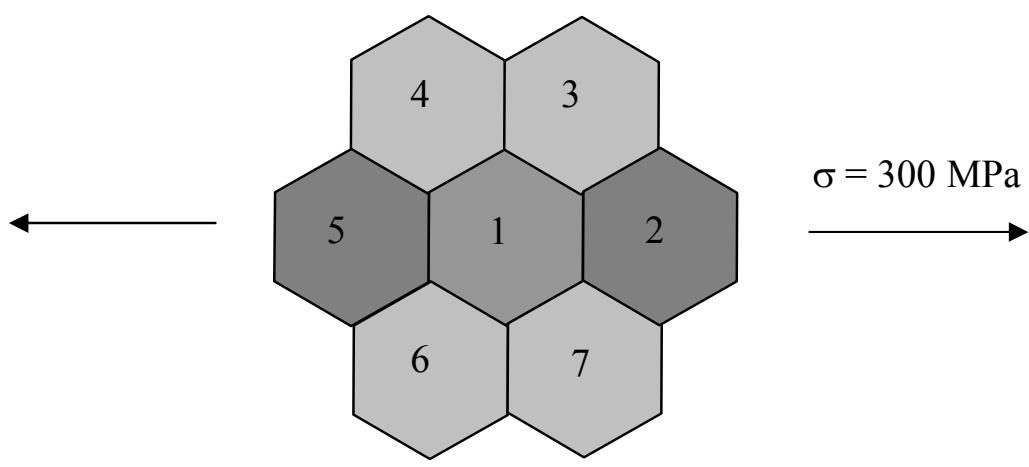

Fig. 8. Simplified configuration of surface neighboring grains leading to the maximal resolved shear stress in the middle well-oriented type B grain (number 1). Grains 3, 4 and 6, 7 are oriented along [100] (soft grains low equivalent Young modulus), whereas grains 2 and 5 are oriented along [111] (hard grains with high equivalent Young modulus). Tensioncompression. 


\section{Answers to the Reviewer $n^{\circ} 1$}

$\underline{\text { Polycrystalline microstructure, cubic elasticity and nucleation of high-cycle fatigue cracks }}$ (M. Sauzay, Th. Jourdan)

The manuscript has been read over by a native speaker which permitted us to improve the article.

Some articles have been added to the references. They describe previous modelling attempts concerning slip distribution in polycrystals and/or crack network formation:

[11] T. Hoshide, D. F. Socie. Crack nucleation and growth modeling in biaxial fatigue. Engineering Fracture Mechanics 29 (1988) 287-299.

[12] G. Cailletaud, V. Doquet, A. Pineau. Cyclic multiaxial behaviour of an austenitic stainless steel: microstructural observations and micromechanical modelling. In K. Kussmaul, D. McDiarmid and D. Socie (eds) Fatigue under biaxial and multiaxial loading. Mechanical Engineering Publications. London (1991) pp. 131-149.

[13] V. P. Bennett, D. L. McDowell. Polycrystal orientation distribution effects on microslip in high cycle fatigue. International Journal of Fatigue 25 (2003) 27-39.

The section "short crack nucleation and early propagation" has been drastically reduced. All equations have been deleted as well as the results and the corresponding figure. Using the copper single crystal Wöhler curve plotted by Kettunen, it is only mentionned that, in the high-cycle fatigue regime, a small variation in the resolved shear stress can induce a large variation in the number of cycles to crack initiation and early propagation.

[30] P. O. Kettunen. Fatigue hardening of copper single crystals at low stress amplitudes. Acta Metallurgica 15 (1967) 1275-1286.

We agree that plasticity anisotropy should be taken into account as well as elasticity anisotropy for computing the plastic slips which have a strong influence on crack nucleation and early propagation. Our study could give estimates of the driving forces for plastic slips i.e. Schmid factors and resolved shear stresses. Finally, estimates concerning the normal stresses could be useful too because normal stresses could assist crack propagation. 


\section{Answers to the Reviewer $\mathbf{n}^{\circ} \mathbf{2}$}

$\underline{\text { Polycrystalline microstructure, cubic elasticity and nucleation of high-cycle fatigue cracks }}$ (M. Sauzay, Th. Jourdan)

The manuscrit has been shortened in order to be more effective (shorter paper, less tables and figures).

The reviewer suggestions have been taken into account:

(1) the manuscript has been read over by a native speaker which permitted us to improve the article.

(2) the word "blocked" has been replaced by "fixed"

(3) the appendix has been deleted

(4) the word "submitted" has been replaced by "subjected"

(5) concerning the relationship between PSB formation and grain size, all the experimental studies showed clearly that in a "reasonnable" grain size range (between $10 \mu \mathrm{m}$ and a few hundred $\mu \mathrm{m}$ ), there is quite no influence of the grain size on the macroscopic PSB threshold (i.e. the minimum macroscopic tension-compression stress amplitude for PSB formation) [21,23-24].

In fact, for small macroscopic stress, only microplasticity takes place, many grains still behave elastically and no real Hall-Petch effect could probably be observed. This correponds to the hypothesis of a matrix which behaves elastically. Therefore, only one parameter is needed: the critical resolved shear stress leading to PSB formation in the grains. As no grain size effect is observed concerning the macroscopic threshold, it seems reasonnable to use a grain threshold which does not depend on the grain size. The mechanism of PSB formation in austenitic steels, predicted by Discrete Dislocation Dynamics and discussed in [25], could explain the independence of the resolved shear stress at the grain scale with respect to the grain scale.

It should be added that for small applied stress, only a few grains present PSBs and the slip bands usually stop at the grain boundaries. But for higher applied stress, numerous grains present PSBs and transmission configurations have been observed (the slip bands located in two neighbouring grains are a little desoriented because of the misorientation between the two adjacent grains).

Finally, Mughrabi and Wang reported that there is quite no influence of the grain size on the CSS curve and fraction of surface grains presenting PSBs. These observations concern higher stress amplitudes. But, concerning the influence of the grain size on the CSS curve, other authors noticed a Hall-Petch effect (see Haddou et al., Fatigue2002, p. 1593-1600). 
In order to clearify this point, some comments and two references have been added:

"The influence of the grain size is not taken into account in our computations concerning microplasticity. Following several observations reported in the literature, this hypothesis seems reasonable. Mughrabi and Wang showed that the grain size has a negligible effect on the and on the measured fractions of grains presenting PSBs (copper polycrystals, small applied strain, grain size range: ) [21]. Hessler [23] (copper) and Cugy and Galtier [24] (ferrite) showed that the grain size has a very reduced influence on the critical macroscopic stress for PSB formation at the polycrystal free surface. The mechanism of PSB formation in austenitic steels, predicted by Discrete Dislocation Dynamics and discussed in [25], could explain the independence of the resolved shear stress at the grain scale with respect to the grain scale. " (p. 17-18)

[21] H. Mughrabi, R. Wang. Cyclic stress-strain response and high-cycle fatigue behaviour of copper polycrystals. In P. Lukas and J. Polak (eds.) Basic mechanisms in fatigue of metals. Elsevier. Amsterdam (1988).

[22] M. Sauzay. Cubic elasticity, microplasticity and high-cycle fatigue crack nucleation in polycrystals. In W. S. Johnson, D. L. McDowell, J. C. Newman and A. Saxena (eds) Fatigue2006. Elsevier. Oxford (2006).

[23] W. Hessler. Wechselverformungsverhalten von vielkristallinem $\mathrm{Cu}$ im bereich hoher Lastwechselzahlen. PhD-Thesis, University of Vienna (1981)

[24] P. Cugy, A. Galtier. Microplasticity and temperature increase in low carbon steels. In A. F. Blom (ed.). Fatigue 2002. Emas. Cradley Heath (2002).

[25] C. Déprés, C.F. Robertson, M.C. Fivel. Crack initiation in fatigue: experiments a,d threedimensional dislocation simulations. Materials Science and Engineering A387-389 (2004) 288-291.

(6) We fully agree concerning the stress redistribution induced by plasticity. In particular, for a given macroscopic strain, the macroscopic stress is reduced if plasticity takes place. And the grain stresses are reduced too. We wanted only to point out that for a given macroscopic stress, the stress in elastically-deformed grains would be higher if plasticity occurs in the matrix and in the surrounding grains than if these deform only elastically. Using an inclusionatrix model such as the simple Kröner one [29], it can be shown that forward stresses appear in elastically-deformed grains whereas backstresses appear in grains which deform plastically more than the matrix (whole polycrystal). It means that, for the macroscopic stress we used in our elastic computations (i.e. $\Sigma=180 \mathrm{MPa}$, see Table 10), the predicted resolved shear stresses in the elastically-deformed grains would probably be higher if plasticity is taken into account. The grain PSB threshold would be reached more easily. Therefore, taking into account plasticity would probably not allow us to explain the anomalous behaviour of nickel grains observed by Blöchwitz et al.. Of course, for a given macroscopic strain, the stresses in grains considered as elastically-deformed would be smaller with plasticity than without. 
In order to clearify this point, some comments and one reference have been added:

"Plasticity effects could not explain the discrepancy observed for nickel. For a given macroscopic stress of Table 10, used in the previous elastic computations, plastic deformation of the surrounding grains and matrix should lead to the formation of forward stresses in the grains which deform purely elastically (Kröner's inclusion approach [29]). Therefore, still for a given macroscopic stress, plasticity would not delay the plastic deformation in elastic grains. Of course, for a given macroscopic strain, the stresses in grains considered as elastically-deformed would be smaller with plasticity than without.” (p. 20)

[29] E. Kröner. On the plastic deformation of polycrystals. Acta Metallurgica 9 (1961) 151161.

(7) we agree that the resolved shear stress is not the only driving force for crack propagation. The normal stress to the crack plane can be influent. This is particularly true if friction takes place along the crack lips, the crack lips present relief or a mixed-mode is considered. That is why the normal stress distributions (average, scatter) were discussed in the manuscript as well as the resolved shear stress distributions. In order to highlight the normal stress effect, we added two comments concerning the influence of the normal stress:

"Finally, the scatter in the normal stress to the crack plane can influence the crack propagation rates in addition to the resolved shear stress scatter." (p. 21)

"If the Schmid factors and normal stresses are close, the scatter can not be explained by neighbor effects induced by crystalline elasticity anisotropy (negligible for aluminium)." (p. 22).

"For the tension-compression loading, uniform horizontal (x-axis) displacements are prescribed at one matrix lateral face which is perpendicular to the x-direction (Fig. 2 a)). The opposite side remains fixed. The four other faces are traction free. The adopted value of displacement corresponds to a macroscopic tensile loading of $300 \mathrm{MPa}$. Another value could have been chosen as the problem is linearly elastic. Some other node displacements are fixed in order to avoid rigid body motion indetermination. In equibiaxial loading, additional ydirection displacements are prescribed at the two sides perpendicular to the y-axis. In torsion, the y-direction (x-direction) displacements at the two opposite sides perpendicular to the $\mathrm{x}$ axis (y-axis) are specified. The two horizontal sides are traction free."

(9) Figs 1, 2(a), 3, 7, 8, 9 have been improved

(10) the labeling y-axis of Fig. 5 has been simplified (" 250 " instead of " $2,50 \mathrm{E}+02$ " for example) 
(11) The manuscrit has been shortened in order to be more effective (shorter paper, less tables and figures).

(12) the word "short" has been removed from the title 